\title{
Hovering on Screen: The WOW-Affect and Fan Communities of Affective Spectatorship on So You Think You Can Dance
}

Elena Benthaus, University of Melbourne

In this article I argue that the television dance franchise So You Think You Can Dance (SYTYCD) fosters and encourages what I call affective viewing practices and communities of affective spectatorship, which are specifically related to the "WOWaffect" created by its affective bodies. I use the term 'affect' to indicate the relationship between screens, athletic/virtuosic bodies, sound, and movement as one of excessive stimulation, resulting in intensities, or affects, which are circulated between screens and bodies as particular moments of suspense. In this sense, affect can be located in the gap between the impact of a stimulation on the skin-surface and a more coherent, cognitive response to this stimulation. The WOW as an utterance in relation to the athletic/virtuosic screen bodies and their affective impact gives voice and physical expression to the excess of intensities as a not-yet-cognitive suspended response. The notion of the WOW-affect, combining the utterance with a specific affective impact, is closely linked to the vaudeville show aesthetics of using an intensely spectacular movement series at the end of a routine to 'stop the show' by stunning the audience and suspending their reaction for a brief moment in time. Hence, the WOW-affect is a particular reaction to the experience of movement. As Kate Elswit argued in relation to SYTYCD, the show "trains audiences in affective dance spectatorship." ${ }^{1}$ According to her argument, this is achieved by contextualizing the dancing bodies within the narrative structure of the format as a whole, the narrative content of the dance routines, and audience attachment to the dancers as people. All of these observations are linked to the way in which reflective language is used throughout the show to narrate these various aspects and not about the movement itself or the dancing bodies. Whereas Elswit proposes that the show "does not privilege the experience of movement ${ }^{\prime 2}$ to create feelings in its spectators and does not examine the way the screen technology itself contributes to the experience of movement, I argue that the bodies in movement, enhanced by the screen technologies, create affective attachment via the WOW-affect. Furthermore, this affective attachment produces communities of affective spectatorship via the presence of the show not only on television but also on social media sites. This media presence, specifically the online presence of the show, fosters engagement across groups of people, who bond with each other in discussions of the affective bodies and performances as part of a constant feedback loop, which revolves around the WOW-affect and the engagement it

The International Journal of Screendance 5 (2015). 
stimulates. My aim in this article is to discuss the relationship between the affective dancing bodies on SYTYCD, the WOW-affect that is created as an intrinsic part of the show, and the way the affective bodies and their virtuosic performances foster communities of affective spectatorship on social media sites that can be considered as dance fan communities.

As audience attachment to the show is positioned as a personal affective experience, which then translates into a shared affective experience on the net, I want to start by considering my own attachment to the format. I first came across SYTYCD when I was studying and dancing in Melbourne and channel TEN started auditioning dancers for the first Australian season at the end of 2007 for its official launch in 2008. Dancers I knew and trained with went to the auditions, and two even made it into the Top 20. Soon after the first episode was broadcast I had to leave and go back to Germany. The dilemma I faced was how to get hold of the episodes in Germany. While searching for a solution, I discovered an American YouTube channel, on which the episodes were posted in 15 min segments alongside the American and Canadian seasons, ${ }^{3}$ which is how I came across the American "original" for the first time and started catching up on the three seasons that had already been broadcast and posted. When YouTube deleted the channel and user profile due to copyright infringements, ${ }^{4}$ the user created a private Facebook group to which people could only get access by "friending" the user and then being added to the group. As a result, this particular spectator-fan community moved from YouTube to Facebook, where members have been following the American, Canadian, and Australian versions and discussing the format and its content within a relatively stable spectator community ever since. ${ }^{5}$

My attachment to the show came about in two distinct steps: The first was personal attachment due to having dancers I personally knew on the show. The second was academic. After becoming familiar with the format and franchise as a whole and its point of origin, I became attached and interested on a scholarly level, due to the variety of dance and dancers featured on the show as well as the way the dancing was filmed. This resonates with Dee Reynolds's observation that identification for dance audiences of televised reality talent shows (she uses Strictly Come Dancing here) is facilitated by an emotional proximity between spectators and the dancers as people, rather than by their dancing moving bodies. ${ }^{6}$ However, the question that arose from my continuing observations and attachment was how this attachment and engagement with the show, which I understand to be part of popular screendance rather than reality talent competitions, is facilitated by the dancing bodies and the screen technologies in more detail. In relation to this I am suggesting that the specific attachment to the suspended athletic dancing bodies creates a particular form of engagement with movements (watching movements and being moved), in which the practice of spectatorship and the identification with a community of spectators becomes affective. Indeed spectators move from a more passive notion of 'spectating' to the active practice of 'fan-ing,' 
which involves a different form of spectatorship, closely related to affect as a trigger for active engagement across screens and sites.

\section{The WOW-Affect}

For considering the way in which the dancing bodies and the screen technologies produce the WOW-affect and further facilitate attachment around these bodies and the participation and engagement with fan communities, the notion of WOW and its affective qualities need to be differentiated in more detail. When Henry Jenkins argues for the appreciation of the complexity and diversity of pop-cultural performances in his book The Wow Climax: Tracing the Emotional Impact of Popular Culture, he says, "consider the singular beauty of the word 'wow.' Think about the pleasure in forming that perfectly symmetrical phrase on your tongue. Imagine the particular enthusiasm it expresses-the sense of wonderment, astonishment, absolute engagement." ${ }^{7}$ Jenkins specifically uses the term "wow climax" to describe the effects of pop cultural performances, a concept that he traces back to the vaudeville tradition, in which it was common to use a spectacular movement series or trick at the end of an act to leave the audience pleasurably speechless. As such it was an important tool for stopping, or suspending the show for a brief moment in time as a result of the audience's emotional reaction and applause. While Jenkins contemplates the particular pleasure and beauty of the word WOW and the way it 'rolls off the tongue,' he does not go into further detail about what specific verbal and physical manifestations the WOW as an affective response can entail. I argue that apart from being an expressive response to something too stunning, too spectacular, too intense, or too emotional to put into more elaborate verbal expressions, the WOW as an immediate physical-verbal expression hovers at the threshold of a more articulated, re-cognized, and verbalized emotional response.

In the season 4 Top 6 episode broadcast on the 24th of April 2014, SYTYCD Australia contestant Michael Dameski performed a highly athletic and virtuosic solo to the track "Unstoppable" by E.S. Posthumus, an independent music group from L.A. that combines classical orchestral sounds with drum rhythms and electronic music. ${ }^{8}$ Announced by host Carrie Bickmore with the words, "he really is unstoppable, it's Michael, ${ }^{\prime 9}$ with the opening bars of the music, the camera cuts from a high angle long shot from the back of the studio to a full shot of Michael on stage. Alongside the opening bars of the track, featuring string instruments playing an eerie melody, Michael is building up intensity and tension with two slow steps forward and circular arm movements to prepare for the first virtuosic move, a back flip to a stretched leg forward bend on the floor. The camera, which focuses on him in a medium shot at the start, displays his face set in a concentrated warrior like expression and cuts to a full shot during the backflip sequence, while the music briefly pauses to start up again with a drumbeat the moment he lands on the floor to pick up the string melody again. From there he moves through a fluid floor sequence into side splits from which he rises to a standing position by sliding his legs together. During this floor sequence the music 
slowly intensifies by drumbeats, added to underlie the string melody, which is being drawn out till the staccato constantly intensifying orchestra-drum-electronic music starts. In a similar way, Michael's movement quality slowly intensifies during the drawn out section culminating in him taking two preparatory steps forward to jump into the air momentarily suspending his body horizontally to the floor before catching the fall in a forward roll in time with the beginning crescendo of the music. His movements in the crescendo section become faster and more staccato as well and the solo ends with him doing four à la seconde turns into a sextuple pirouette landing on the floor.

This highly virtuosic and highly athletic performance resulted in a myriad of WOW reactions, both verbal and physical. The studio audience had already started screaming unintelligibly at the top of their lungs during the solo, while judge Paula Abdul cannot stop screaming, "OH MY GOD," ${ }^{10}$ judge Jason Gilkinson is captured merely clapping with a stunned jaw-dropped expression on his face, and the studio audience is chanting "Michael." The physical responses include extensive clapping, stomping of the feet, jumping up from seats and various other gestures of disbelief, including tears, literally stopping the show for a good 10 minutes, which were edited out for the actual broadcast. The moment ended with Carrie Bickmore summing up the reactions by saying, "you just blew us away. Wow!"11 This moment not only exceeds the usual scripted applause of shows like this, ${ }^{12}$ but is, for as long as I have been following the show, the only solo performance of the SYTYCD franchise that has gone viral by being shared across various forms of social media, fan communities, and news media sites, triggering more written out WOW responses in turn. Executive producer Nigel Lythgoe tweeted in response, "one of the best \#DanceForYourLife Performances I have ever seen on \#SYTYCDAU, or anywhere for that matter, ${ }^{\prime \prime 3}$ which was retweeted 249 times and in combination with other tweets resulted in Michael's solo temporarily trending on Twitter. As a result of this solo and Michael winning the show, he was invited to perform this solo at the finale of SYTYCD US season 11. Referring to the social media hype surrounding his solo performance, Paula Abdul introduced Michael with the words, "but there is this one man, young man in particular, who harnessed a passion into a performance that was so breathtaking. Not only did everyone rise out of their seat, but everyone you could hear [she makes a gasping sound] that gasp and the video of his performance went viral around the world. ${ }^{14}$ Considering these responses in relation to the WOW, the WOW-affect triggered by the dancing bodies on screen is immediately visible and audible in the on-screen spectators as part of the broadcast. This in turn heightens the experience of the WOW moment for the spectator-at-home and is an intrinsic part of the transmission of affect across screens, which I will theorize by drawing on Brian Massumi's Deleuzian take on affect and Sara Ahmed's notion of impression. 


\section{Affective Bodies and the WOW Affect}

Discussing the relationship between body, movement, and feeling, Brian Massumi notes that language as verbal expression is not in opposition but in a differentiated relation to what he describes as intensity/affect, and furthermore depends on its relation to image perception. According to Massumi, seemingly objective, factual language interferes with and decreases the sensational or tactile effect of images, whereas emotional utterances enhance their intensity. For Massumi, intensity/affect suspends linearity for a moment in time. This emotional state is a state of suspense, in which all of the body's senses are fully alerted, creating a moment of non-linear hovering before progressing to a more cognitive response. Intensity/affect is not passive, because suspense is a state of motion, vibration, and hovering in between states. Nor is it completely active, because the moment of suspense is not-yet directed toward a means or an end. It is an excess of linear progression and not-yet signifiable. ${ }^{15}$ If it is not-yet-signifiable, intensity/affect is also unlike emotion, which is already signified, consciously expressed and fixed qualifications of content. Or, in Massumi's words, "it is intensity owned and recognized." ${ }^{16}$ Thinking of WOW as a verbal expression or reaction to the intensity of performances (where performances are seen as stimulators), WOW becomes a verbalized excess of that intensity within the body. As such, it is not a specific emotional utterance, which gives voice to a cognitively recognized particular emotion, but an expression of excess of corporeal intensities. It is not yet directed toward a specific goal, but is an excess of affect, a suspended response, which hovers in between and before conscious cognition. This conception of an excess of intensities is linked to the moments of suspense, which Massumi locates in "the missing half-second, ${ }^{17}$ that is, the lapse of time between the stimulation of the skin and the conscious registration of that stimulation as a reaction to an action. As Massumi argues, "the half-second is missed not because it is empty, but because it is overfull, in excess of the actually performed action and of its ascribed meaning. ${ }^{18}$ This notion of excess of intensities positions the body as the first instance of cognition before re-cognition (of emotion) sets in. The excess is the potential of possible expressions of these intensities. The moment in between this potential and conscious (re)-cognition is the missing half-second (which is constantly missing), or in other words every suspended moment in between potential and (re)-cognition. In relation to the affective capabilities of popular screen dance bodies, in the 'in-between-ness' of these two poles moments of suspense are realized, or corpo-realized by WOW movements of the virtuosic, athletic dancing bodies, which exude a corporeal athletic excess on screen. Going back to Michael's solo, the experience of intensity constantly increased during the performance due to the excessive physical virtuosity of his body and the excessive power of the music, culminating in the WOW as an expression of this corporeal and emotional suspended excess. 
Linking displays of athleticism to spectatorship and notions of beauty and joy, Hans Ulrich Gumbrecht sees intensity as a key aspect of the affective potential of what he calls "athletic beauty." ${ }^{19} \mathrm{He}$ not only refers to the intensity with which spectators become engrossed in watching sports and following a team or an individual athlete, but also the intensity with which athletes execute movements. Gumbrecht calls this "focused intensity," ${ }^{20}$ which is specifically linked to corporeality, the focus of the athletic body on what is ahead within the confinement of the event in question, and on the transmission of this intensity and focus to the spectator. For the performer/athlete it is about pushing and exceeding physical limits, hovering just at the edge of what seems physically possible. On SYTYCD, Michael's face as well as his body display the focused intensity Gumbrecht mentions. The intensity is written into the lines of his face and the visibly tense and high-strung muscles, all of which expresses something hovering in between grim determination and concentration and as a result gives him a warrior-like look. As an expression used in contemporary dance, hovering refers to a specific movement quality ${ }^{21}$-pushing movements to their extreme suspension, when the body's senses and muscles are fully alerted and tensed, and then falling off-center, transferring and continuing the flow of movement. Hovering provides the tipping point into new potential. Instances of suspended hovering in combination with hypervirtuosic movements are an intrinsic part of popular screen dance performances as displayed by Michael in his solo. His body is constantly hovering and suspended in midair, resulting in a spectating experience of hovering on the edge of the WOW-affect before moving into more consciously cognitive territory. Hovering thus becomes a part of affective spectatorship, located in the gap of suspense where affective and possibly emotional potential is realized.

It is here, in the gap, where the screen-as-interface via the skin-as-interface becomes important for the transmission of affect. ${ }^{22}$ The skin of the spectator-at-home works in relation to the interface-skin of the screen and the dancing bodies on the screen as a means of affective intensification. Sara Ahmed, elaborating on the notion of skinsurface-interface in relation to how affect, intensities, and emotions pass in-between bodies, positions emotions as being neither something within a subject nor without a subject, but occurring at the border between inside and outside. In other words, they are hovering. ${ }^{23}$ This is something that happens at the surface of things, and with regards to human bodies, at the skin, which Ahmed pays particular attention to. As she notes, "even the most apparently direct sensations, or impressions are mediated, involve traces of past impressions on skin surfaces." ${ }^{24}$ The skin is here established as the border between inside and outside that is made and unmade in the event of being im-pressed upon by experiencing sensations due to being in the proximity of other bodies or other skin surfaces. The key word that Ahmed uses in relation to skin surfaces is the word 'impression,' with the term 'press' at its core. 'Press' is understood as leaving a mark, or a trace "by the press of one surface upon another" 25 and relates to the 'impression' other body-skin-surfaces leave behind. To bring Massumi and Ahmed 
together then, the moment in which the skin is im-pressed upon (stimulated) creates suspended intensities and potentialities of sensations that trickle into being emotionally im-pressed upon at what Massumi referred to as the deeper corporeal level (below the skin). It is here, below the skin, where affect and cognition hover for a moment before re-cognition of a possible emotional content eventually sets in. The trace of im-pression left behind is the tingling of the skin as a re-action to being impressed upon.

When watching Michael Dameski's solo for the first time, I felt the impact of the eerie string melody combined with the focused intensity of his facial expression and the 'ready-to-go' muscular tension of his body as a slight tingling of the skin at the back of my neck and the base of my scalp first. Once the staccato rhythm of the music, the pace and athleticism of his movements, and the on-screen audience's noise level picked up and built towards the final crescendo, the tingling moved down the skin of my arms resulting in goose bumps. The important observation here is that while the music in combination with the movements resulted in a tingling skin surface, the experience was even more intensified due to the noise level of the on-screen audience, which was part of the sound transmission of the screen and established proximity between my body, Michael's dancing body and the on-screen spectating bodies. Considering this, the skin is experienced as the point of 'contact' (stimulation) where transmission of affect occurs.

The WOW as a physical-verbal response to dancing bodies and an indicator of being in a suspended moment of being WOW-ed is linked to an affective response and to the transmission of affect across screen-interfaces and body-surfaces. Considering it as an affective reaction to movement, the WOW-affect expresses an excess of intensities within the body, without however being a specific cognitively registered emotional response. In contrast to the notion of kinesthetic empathy in which it is assumed that spectators always empathize with the choreographed moving bodies of a dance work by reproducing in one's mind the movement and feelings of the dancing body, I argue that the transmission of affect in relation to popular screen dance performances is located in the experience of a lack of empathy. In Choreographing Empathy Susan Foster challenges the idea that there is a natural connection between dancing and spectating bodies by revealing the constructed, mediated and historically specific circumstances of the connection between choreography, kinesthesia, and empathy by looking at the way that the meaning of these terms has radically shifted over time. As she argues, "to 'choreograph empathy' thus entails the construction and cultivation of a specific physicality whose kinaesthetic experience guides our perception of and connection to what another is feeling." ${ }^{26}$ As such, the three separate yet linked concepts of choreography, kinaesthesia, and empathy are responsible for constructing a particular corporeality in different social, cultural, and historical contexts, all of which are still linked to a sense of empathy, or fellow-feeling, as part of the dancer-dancespectator relationship. ${ }^{27}$ As Foster argues, "most crucially, they [the examples she uses] 
demonstrate the many ways in which the dancing body in its kinesthetic specificity formulates an appeal to viewers to be apprehended and felt, encouraging them to participate collectively in discovering the communal basis of their experience. ${ }^{28}$ In this sense, empathy is not supposed to simply relate to feeling what someone else feels (the emotional and psychological aspect), but about the particular attention to and awareness of the physical changes during processes of empathy and in turn to power relations and communal relations between empathizing bodies. The kinaesthetic experience in her analysis is an important factor. It is still nevertheless based on the empathetic, fellow-feeling experience of the kinaesthetic corporeality of the dance in question and not on an affective experience of the kinaesthetic momentum and the possibility of a suspended response because of experiencing an excessive intensity due to excessive stimulation, all of which is part of the pleasure of watching popular screen dance performances. This pleasure and the resulting attachment to popular screen dance performances occur at the level of the transmission of affect, by being affected by the virtuosity and athleticism of the dancing bodies. In other words, the dancing bodies potential to WOW suspends both, a potential empathetic as well as a possible emotional response.

To return to Michael's solo, even after the tingling skin and the goose bumps subsided, the excessive intensity this performance left behind could not be connected to a specific emotion. I felt stunned and WOW-ed but not very emotional or empathetic but rather intensely affected and stimulated. To extend the argument further, the pleasure of watching popular screen performances occurs from being affected by the virtuosity and athleticism of the dancing bodies; not necessarily because the spectator-at-home can imagine to empathetically inhabit this particular athletic moving body, but because he/she cannot due to being WOW-ed. The WOW-affect, rather than functioning as an emotional or empathetic response, suspends emotion and empathy, building up sensation and intensity to hover before the tipping point into cognition. It is still a form of kinesthetic sensation, but based on affect and not necessarily based on empathy. The WOW as a verbalized response is indicative of an absence of empathy, because the spectator-at-home is wowed and stunned by the impossibility of imagining inhabiting this body while still experiencing the rhythms produced by the movements, the music, and the noise of the on-screen audience.

In his analysis of Kingston's dancehall scene that explores how movement, feeling, and affect are related and transmitted as rhythmic patterns of frequencies, Julian Henriques proposes that "affect is expressed rhythmically-through relationships, reciprocations, resonances, syncopations and harmonies." ${ }^{29}$. Rhythm is used here to describe the possibility of affect to transfer across media. Moreover, rhythm is related to a visceral experience of the crowd, experiencing the rhythm and vibration of the sound and its relationship to bodies in movement as "transsensorial perception. ${ }^{\prime \prime 3}$ The transsensorial experience arises from what is perceived via auditory senses and simultaneously experienced as kinetic movement of embodying rhythmic vibrations of sound in dance. 
The vibrations created via sound and movements are in constant flow between bodies and it is this flow of vibration and movement that results in a transmission of affect across bodies and indeed, in relation to what I argued earlier, across screen and skin surfaces. In relation to popular screen dance aesthetics and its affective bodies, the transmission of affect does not solely rely on the visual images on screen for creating intensities and 'WOW' moments, but is produced through the combination of the visual images of the dancers' bodies in motion and the sound, or music, to which these bodies in motion are choreographed, and the additional noise/sound level of the on-screen audience. Hence, rhythmical kinetic patterns of moving bodies resonate with and alongside the rhythmical frequencies of the sound, which result in affective vibrations that are transmitted across screen and skin surfaces. ${ }^{31}$ The screen and recording technologies serve as a magnifying glass and enhancer of these experiences, moving spectators from simply being WOW-ed to actively engaging with other spectators to share the WOW-affect and to move further into the cognitive processes of "making sense."

\section{Communities of Affective Spectatorship: Dance Fans and Joy-ful Objects}

As indicated by the notion of the WOW affect, there is something sensuous, sensational, tactile, and contagious about watching the affectively athletic movements of the dancing bodies on SYTYCD. The contagious and affective capabilities are enhanced and magnified by the screen, in order to hover over and transcend the screen to affect the spectator-at-home into excess activity. In some cases this excess activity results in the active engagement with a spectatorship community dedicated to these affective viewing experiences. Due to the increasing online presence of the show in the last few years, changes in contemporary viewing practices, and the migration of viewers and communities to social media sites and the Internet, ${ }^{32}$ personal engagement in the same space with others is replaced by the personal-virtual engagement of viewers across screens, in which online fan communities facilitate sociability and community around a specific text. Assuming that affective contagion stops with the mere 'passive viewing' of SYTYCD and interactive voting for favorite routines and contestants underestimates the active participation and engagement with its content beyond these acts. Specifically, it erases international spectators, who cannot vote because of their location outside of the U.S. Such spectators watch the show on their computer screens, the episodes of which are embedded in a closed, yet expanding Facebook group, as my anecdote from the beginning indicated. Considering the active engagement and participation with the show, with dance, and with other users within the community of the Facebook group, it might be more productive to think of the spectators as fans and of the Facebook group as a fan community, or a dance fandom. These dance fans are not just fans of dance, in which dance can be anything, but also 
fans of dancers and fans of a specific type of dance-text, not just SYTYCD, but also popular screen dance texts in general.

The notion of 'fans' in relation to dance practices does not really exist, or is not used when talking or thinking about dance audiences and the way that spectators perceive dance performances. It is more common to simply refer to dance audiences as simply spectators or the more 'culturally refined' terms aficionados or connoisseurs, or what Dee Reynolds differentiated as more or less dance-literate audiences, even when talking about popular screen dance performances..$^{33}$ In one of the earliest academic monographs dealing with fan cultures and a key text in fan studies, Henry Jenkins starts his account and re-positioning of fans and fandoms in his book Textual Poachers: Television Fans \& Participatory Culture by starting with the Oxford English Dictionary meaning of the word 'fan,' specifically as being derived from "fanatic" 34 and as such indicating an emotionally invested, active, and processual state. As Jenkins further proposes, processes involved in being active as a fan, include creating a close proximity with the text in question, practices of reading and re-reading these texts, and social interactions drawing on and including the text. ${ }^{35}$ These practices are processual because they involve a constant re-reading and re-engagement with the text, texts related to the text, and other fans. The circulation of information is here akin to a constant flow of movement in, with and through the text. Proximity to a text does not mean that spectators lose the ability to critically assess the text and become aware of potential entanglements, which might turn them into passive consumers. Quite the contrary, proximity as the state of being invested in and affected by a text creates and opens up the potential to see it critically. As Jenkins argues, "these relationships between readers and texts are continually negotiated and viewers may move fluidly between different attitudes toward the material." ${ }^{136}$ This observation is made with reference to Roland Barthes's understanding of the open-endedness of texts as "a galaxy of signifiers. ${ }^{137}$ In other words, the plurality of meanings or readings (because each reading of the text re-negotiates and re-positions the meaning of a text) exists in an endless, permanent present: a virtual sphere of possibilities not unlike the virtual and actual sphere of potential affects, hovering above, under and across multiple surfaces and interfaces.

Indeed, as Barthes noted, re-reading and hence, re-negotiation can be seen as an unruly, defiant, and resistant practice, ${ }^{38}$ which plays with the text and its plurality of meanings and effects. Moreover, as I would argue, re-reading as a practice also plays with a plurality of affects in order to move further and beyond the surface of the text. As a result, both affects and fans are caught in a state of constant hovering between surfaces and interfaces. Instead of dismissing a text if it becomes uncomfortable or is changed to its disadvantage, fans stick with the material and this form of attachment is the basis for a constant renegotiation of the relationships between effects and affects and other fans. Considering this, the notion of being a fan of something is positioned as an experience with a high emotional involvement and investment; hence the notion of 
fan always has an affective dimension. In his article "IS THERE A FAN IN THE HOUSE: The affective sensibility of fandom," Laurence Grossberg stressed this affective dimension, or sensibility, as a powerful aspect within fandoms of popular culture. Also arguing against the idea that audiences are passive consumers, he emphasized, "the relationship between the audience and popular texts is an active and productive one." 39 This relationship hinges on affective investment, in which the specific context of the fan text becomes soaked with affect..$^{40}$ This affective investment circulates, or rather hovers between fan, fan text (in the case of SYTYCD the dancing), and fan community, in which meaning is constructed within that space of in-between-ess.

In relation to Michael's solo, most of the comments reiterated the same point of being im-pressed with his athletic and virtuosic performance. Member fan K.B. wrote, "it gives me goose bumps every time I watch it J." ${ }^{41}$ While M.B. noted a little further down, "watched it AGAIN for like the 11th time... still impressive. ${ }^{42}$ Both the skin as the point of contact for the transmission of affect and the continuing potential for this impression when re-watching, or re-reading the performance are commented upon here. Moreover, none of the comments identify a specific emotion, only the stunning affective impact the performance leaves behind. Attachment and a sense of community are created within an active state of participation and engagement, which has been discussed in various studies of fandom, and indeed is a building block for engaging with practices of fan spectatorship. ${ }^{43}$

Returning to the act of viewing then, in contrast to the proposition that broadcast television viewing is less about viewing and more about the distracted glancing at the screen while doing other things, ${ }^{44}$ fan-spectators choose to watch the episodes posted online consciously, as for some member-fans this is the only way they can access SYTYCD because of living outside the U.S. But even the American members of the group choose to view the episodes in the online segments because of their participation in a community of spectators who actively engage with the show and each other in order to share opinions, feelings, and knowledge about the individual aspects of the show and dance. The current number of member-fans in the group is 3277 and its number is constantly fluctuating as new members are added. So far I have counted members located in about 33 different countries and across all continents. ${ }^{45}$ Some members' profiles indicate a dance background, either professional or recreational, indicating an accumulation of a variety of knowledges. One of these aspects is related to knowledges of the dance styles presented on the show, specifically Bollywood, or the as Ballroom qualified dance styles (specifically those adapted from a Latin American background). As O.D. a very active member-fan from India noted in the comments section underneath Ricky and Valerie's Bollywood routine from Season 11, Episode 9:

It's actually very difficult to explain 'Bollywood'. Yes, it's usually energetic, involves a lot of hand and hip movements. But one essential quality is that there is an element of acting coz we literally translate the song (not usually 
only music) word for word through the dance. This is somewhat different from the styles that we see here. More than their dance, those fake expressions put me off. ${ }^{46}$

She later posted a link to an Indian Bollywood clip to show the difference from the SYTYCD routine. In this instance, being disappointed with the show's take on Bollywood and the confusion about how to describe this style and how it would look like in an Indian context motivated O.D. to share her knowledge of the style and the way it is understood in a different locality with the other members of the community.

In a similar instance, B.R. a member-fan from Brazil shared their knowledge of Samba when commenting on Malene and Marcquet's Samba in Season 11 Episode 6, resulting in a little exchange with O.D., the Indian member-fan:

Yeah, but here in brazil we have the samba that people dance in carnaval (this one is more common for people to know), with costumes and lots of foot work but we also have the ballroom samba that we call 'samba de gafieira' and this is the one i'm comparing the routine with.

Like this https://www.youtube.com/watch?v=9g-Tnic17RQ. (4.07.2014 at 13:58h)

$-B R$

Making people understand the subtle nuances of something that is so a part of your life and not theirs is extremely difficult as I know very well whenever they dance Bollywood. Thanks for trying to make us see. B. (11.07. at $6: 40 h)^{47}$

$-O D$

As fans share their cultural knowledge with an increasingly globalized dance community on the Internet, they set images, affects, bodies, opinions, and comments in constant virtual flow, hovering on screens and in-between screens as part of the affective experience of sociability and community focused around the fan-text.

This flow and the resultant engagement with the content of the text is a critically engaged reading of SYTYCD, its virtuosic and affective dancing bodies, and the WOWaffect of the show as it has progressed through the seasons. From my own perspective and viewing experience, with each new season the show has not only become more glossy, which is partly due to the introduction of HD technologies, but also more generic in its virtuosity and athleticism. Due to the increasing virtuosity and athleticism of the contestants, the production of WOW-moments within the show has increased without necessarily producing a similar amount of attachment with the contestants and WOW-affects in relation to the routines on the side of the fan community. This can be specifically observed in comments reflecting on season 11 in comparison with earlier, 
less glossy and generic seasons, specifically seasons 2-4. As G.Mc observed in relation to Tanisha and Rudy's Jazz routine (S11 Ep. 7):

I fell into the SYTYCD youtube trap last night and was watching some clips from previous seasons and noticed the dancers were just on another level, and so was the choreography. Are the dancers from previous seasons more versatile or just more mature? Old choreographers less lenient/more creative? Or is it the fact that the dancers had more of a chance to develop over the season because they had more screen time? (11.07.2014 at 2:07h) ${ }^{48}$

- G.M.C

In this and in other related comments it can be observed that the most active memberfans all refer back to earlier seasons in order to elaborate on the decrease of the affective-ness and the WOW-affect in the most recent seasons. Instead of decreasing the attachment to the show, however, it fosters the interest-excitement feedback loop in the show by being able to re-call, discuss and share earlier WOW-affects, bodies, and personalities. Part of the WOW-affect in these instances is the re-production of the WOW when re-watching, re-reading, and re-sharing routines within the community. As such the affective-ness of the WOW is created within the shared experience of the fan community and its critically engaged fan practices, in which FOX is discussed as trying too hard to please a mainstream mass audience in relation to the most recent seasons. Indeed, as member-fan S.B. noted in a comment, the show has become "too vanilla/commercial in order to please the masses (and get ratings)." ${ }^{49}$

\section{Conclusion: The Joy-ful Community}

As demonstrated in this article, attachment with SYTYCD can be seen as an affective experience facilitated by moments of suspense and hovering, created by the WOWaffect of its dancing bodies. This experience is enhanced and further magnified by the potential of being part of a fan community in which the shared affective experience, resulting from an engagement with other spectator-fans, is facilitated through and across multiple screens due to the show's presence and availability on multiple different sites and media. The most powerful affective dimension that is shared here, even when aspects of the show are criticized, is the notion of joy and enjoyment, produced by actively engaging with other members of the fan community. The constant inter-action with each other and the dancing bodies intensifies the excitement about, and as a result, the enjoyment of these bodies and SYTYCD as a whole. In other words, the shared enjoyment and mutual excitement is multiplied with all those spectator-fans that watch the show and engage with the community. As a result, joyful attachment is created across a multitude of inter-faces and screen surfaces, in which the WOW-affect hovers and moves in between screens and fans. Feeling joy-ful, or being full of joy, means that this excess of intensities flows over and affects further active engagement and participation across screens, creating the notion of dance fans in relation to screen 
spectatorship. In contrast to the WOW factor, which is circulated as a kind of brand of SYTYCD, the WOW-affect is created in a space of in-between-ness, motion, and hovering between fan text, multiple screens, and fan communities in which a multiplicity of voices are constantly re-negotiated.

\section{Biography}

Elena Benthaus is a PhD candidate at the School of Culture and Communication at the University of Melbourne. She has a M.A. in English Literary Studies and Theatre Studies from Humboldt University Berlin and Freie Universität Berlin and a degree in Modern and Contemporary Dance. Her research project is concerned with the affective presence and presentation of dance on the popular screen and its impact on spectatorship communities on social media.

\section{Notes}

${ }^{1}$ Kate Elswit, "SYTYCD Does Dance Studies," 136

${ }^{2}$ Ibid. 135

${ }^{3}$ For private user-generated YouTube channels, it is not possible to upload more than about 15-minutes long videos onto the site.

${ }^{4}$ This was before FOX had its own channel and started posting the individual dances, but also before they encouraged this kind of online engagement with the show to gain momentum from it by also creating Facebook, then additionally Twitter and now additionally Instagram accounts for each season's Top 20 contestants in addition to online voting and creating an app. This development has been happening roughly since season 7.

${ }^{5}$ In this group, I am just following discussions and comments underneath the clips without contributing to get a sense of the flow of the ideas and emotions circulating about the individual dancers and routines. Because I'm a passive observer-participant in that group, I am not able to disclose the full names or identities of the members of that group in my quotes in this article and will just use initials.

${ }^{6} \mathrm{cf}$. Dee Reynolds, "Glitz and Glamour," 22.

${ }^{7}$ Henry Jenkins, The Wow Climax, 1.

${ }^{8}$ For a look at Michael's solo performance, see the following link. Unfortunately, the video does not include the audience's reaction at the end. A clip including this is not available on YouTube. https://www.youtube.com/watch?v=js4R2Nc_NFA 
${ }^{9}$ Carrie Bickmore, SYTYCD AUS $S_{4}$.

${ }^{10}$ Paula Abdul, SYTYCD AUS 54.

${ }^{11}$ Carrie Bickmore, Ibid.

${ }^{12}$ Apart from comments underneath the video on the SYTYCD-MG fan community stating that about 10 minutes of audience reactions had to be edited out of the recording for the final broadcast version, this was additionally stated in a news item on Australian TV blog tvtonight, which is run by David Knox. See: tvtonight.com.au, "Breathtaking routine brings So You Think You Can Dance to a standstill." http://www.tvtonight.com.au/2014/o4/breathtaking-routine-brings-so-you-think-youcan-dance-to-a-standstill.html

${ }^{13}$ Nigel Lythgoe. Twitter. 25/04/2014 at 06:20 hours. https://twitter.com/dizzyfeet/status/459683484739448832

${ }^{14}$ Paula Abdul, SYTYCD USA S11 E15

${ }^{15}$ cf. Brian Massumi, Parables, 27-28.

${ }^{16}$ Ibid. 28.

${ }^{17}$ Ibid. 29.

${ }^{18}$ Ibid. 29.

${ }^{19}$ Hans-Ulrich Gumbrecht, In Praise of Athletic Beauty.

${ }^{20}$ Ibid. 51.

${ }^{21}$ I draw this notion of hovering in contemporary dance from my own practice and training as a modern and contemporary dancer. Various teachers I have worked with have used this expression to explain how the body is held in suspense as part of its movement processes. Even in moments of stillness the body hovers over, before and in between the next movement. In theoretical writings, the word is occasionally used, but not established as a specific concept.

${ }^{22}$ Massumi argues that stimulation results in increased intensity spreading across the skin as a "generalized body surface." Parables, 25.

${ }^{23}$ cf. Sara Ahmed, "Collective Feelings," 25.

${ }^{24}$ Ibid. 27.

${ }^{25}$ Ibid. 30.

${ }^{26}$ Susan Leigh Foster, Choreographing Empathy, 2.

${ }^{27}$ cf. Foster, 13.

${ }^{28}$ Ibid. 218.

${ }^{29}$ Julian Henriques, "The Vibrations of Affect," 58.

${ }^{30}$ Ibid. 69.

${ }^{31}$ Because of the general noise level that is asked of and maintained by the on-screen audience as part of the taping experience, a silent, because mesmerized, on-screen audience is equally affective. During Ricky and Jessica's Contemporary routine in SYTYCD (USA) season 11, episode 6 the on-screen audience hardly made a noise. The beauty and serenity of the duet had a mesmerizing almost reverent effect, which could be felt through the screen and can be seen in the comments section in the FB group. 
Producer Nigel Lythgoe was equally shocked by the silence because it defied what the studio audience is usually required and hyped up to do.

32 cf. Jonathan Gray et al, Fandom, 7.

33 cf. Dee Reynolds, "Glitz and Glamour," 20.

${ }^{34}$ cf. Henry Jenkins, Textual Poachers, 12-13.

35 cf. Ibid. 53 .

${ }^{36}$ Ibid. 65 .

${ }^{37}$ Roland Barthes, $S / Z, 5$.

${ }^{38}$ cf. Ibid. 15 .

${ }^{39}$ Lawrence Grossberg, "IS THERE A FAN IN THE HOUSE," 582.

${ }^{40} \mathrm{cf}$. Ibid. 586.

$4^{11}$ K.B. on the Facebook Group "SYTYCD Mega Group," 3oth of April 2014 at 23:52h.

$4^{2}$ M.B. on the Facebook Group "SYTYCD Mega Group," 7th of May 2014 at 19:37h.

${ }^{43}$ For more details on the study of fans, see: Henry Jenkins, Textual Poachers: Television Fans and Participatory Culture (1992); Camille Bacon-Smith, Enterprising Women: Television Fandom and the Creation of Popular Myth (1992); Lisa Lewis (Ed.), The Adoring Audience: Fan Culture and Popular Media (1992); Jonathan Gray, et al, Fandom: Identities and Communities in a Mediated World (2007); and Karen Hellekson and Kristina Busse, Fan Fiction and Fan Communities in the Age of the Internet (2006).

${ }^{44}$ cf. Shimpach, "Viewing," $74 \mathrm{ff}$.

${ }^{45}$ By clicking on the "Member" tab, a list of all the members is available and it is possible to click on the individual names and thus access their profiles. Depending on the privacy settings of each individual member, if their "About"-section is publicly accessible, it sometimes includes their current location and other details.

${ }^{46}$ O.D. on the Facebook Group "SYTYCD Mega Group," 25th of July 2014 at $06: 14 \mathrm{~h}$. 47 "SYTYCD Mega Group," SYTYCD (USA) Season 11 Episode 6, July 2014.

$4^{8}$ G.Mc. on the Facebook Group "SYTYCD Mega Group," 11th of July 2014 at 02:07h.

49 S.B. on the Facebook Group "SYTYCD Mega Group," 31st of August 2013 at 06:26h.

\section{References}

Ahmed, Sara. "Collective Feelings. Or, The Impressions left by Others." Theory, Culture \& Society 20.2 (2004): 25-42.

Bacon-Smith, Camille. Enterprising Women: Television Fandom and the Creation of Popular Myth. Philadelphia: University of Pennsylvania Press, 1992.

Barthes, Roland. S / Z. Trans. Richard Miller. New York: Hill and Wang, 1974. 
Elswit, Kate. "So You Think You Can Dance does Dance Studies." TDR: The Drama Review, 56.1 (Spring 2012): 133-142.

Foster, Susan Leigh. Choreographing Empathy: Kinesthesia in Performance. London; New York: Routledge, 2011.

"fan, n.2." OED Online. June 2014. Oxford University Press. Accessed July 31, 2014. http://www.oed.com.ezp.lib.unimelb.edu.au/view/Entry/68ooo?rskey=fOg6z8\&result= 2\&isAdvanced=false.

Gray, Jonathan, Cornel Sandvoss, and C. Lee Harrington. Fandom: Identities and Communities in a Mediated World. New York: New York University Press, 2007.

Grossberg, Lawrence. "IS THERE A FAN IN THE HOUSE: The Affective Sensibility of Fandom." The Celebrity Culture Reader. Ed. P. David Marshall. New York: Routledge, 2006. 581-590.

Gumbrecht, Hans Ulrich. In Praise of Athletic Beauty. Cambridge, MA: The Belknap Press of Harvard University Press, 2006.

Hellekson, Karen and Kristina Busse, Fan Fiction and Fan Communities in the Age of the Internet. Jefferson, N.C.: McFarland \& Co., 2006.

Henriques, Julian. "The Vibrations of Affect and Their Propagation on a Night Out on Kingston's Dancehall Scene." Body \& Society 16.1 (2010): 57-89.

Jenkins, Henry. Textual Poachers: Television Fans and Participatory Culture. New York: Routledge, 1992.

. The Wow Climax: Tracing the Emotional Impact of Popular Culture. New York: New York University Press, 2007.

Knox, David. "Breathtaking routine brings So You Think You Can Dance to a standstill." tvtonight.com.au. Accessed 12th February 2015.

http://www.tvtonight.com.au/2014/04/breathtaking-routine-brings-so-you-think-youcan-dance-to-a-standstill.html

Lewis, Lisa (Ed.), The Adoring Audience: Fan Culture and Popular Media. New York: Routledge, 1992.

Lythgoe, Nigel. @dizzyfeet. Twitter. Accessed 12th February 2015. https://twitter.com/dizzyfeet/status/459683484739448832

Massumi, Brian. Parables of the Virtual: Movement, Affect, Sensation. Durham; London: Duke University Press, 2002. 
Reynolds, Dee. "'Glitz and Glamour' or Atomic Rearrangement: What Do Dance Audiences Want?" Dance Research 28.1 (2010): 19-35.

Shimpach, Shawn. "Viewing." The Handbook of Media Audiences. Ed. Virginia Nightingale. Chichester; Malden, MA: Wiley-Blackwell, 2011. 62-85.

So You Think You Can Dance (US), Seasons 1-11. Television Program. FOX. Broadcasted from 2005-2014.

So You Think You Can Dance (AUS), Season 4. Television Program. Network Ten. Broadcast 2014.

"SYTYCD Mega Group." Facebook. Accessed 12th February 2015. 